\title{
A NEW HITECH COMPUTER-CHESS SUCCESS
}

\author{
ICCA Communication
}

by Hans Berliner

Carnegie-Mellon University's Hitech chess computer scored 5-1 in the National Open Chess Championships held in Chicago, March 18-20. The Championship Section in which Hitech competed had 380 entries. There was a six-way tie for first, with 5.5 points among: IGM Mikhail Tal (a former World Champion), IGM Sergey Kudrin, FM Michael Brooks, IM James Rizzitano, IM Calvin Blocker, and IGM Leonid Shamkovich. Tied for $7^{\text {th }}$, with 5 points each were: NM Hitech, IGM Maxim Dlugy, IGM Walter Browne, IGM Arthur Bisguier, and nine others. Hitech also finished ahead of one IGM. All the above named humans are among the top 30 players in the U.S. No computer has ever finished this high in such an elite company. Its score was achieved by beating 4 Experts, 1 Master, and losing to IGM Kudrin.

Hitech's U.S. Chess Federation (USCF) performance rating for this tournament was 2476, and its rating should rise to USCF 2396, a new high-water mark for computer chess. This places it within 4 rating points of becoming a USCF Senior Master, the highest title that can be awarded nationally in chess. It also means that Hitech is now ranked about 150th among registered U.S. chess-players. This tournament is Hitech's best performance ever since finishing first in the Pennsylvania State Championship in August, 1987. Over its last five tournaments since August 1987, Hitech has achieved a performance rating of 2460. Over this span, it has scored 17-1 against players rated below it, and 3-8 against players rated above it ${ }^{1)}$. Among the eight points it lost against players rated above, three were losses to IGMs, three were losses to IMs, and there were two draws against IMs.

The table below summarizes these accomplishments:

\begin{tabular}{|lllllll|}
\hline Tourney & Score & Place & Highest Beaten & Lowest Lost to & Prf. Rtng. \\
\hline Penna.State & $4.5-$ & 0.5 & $1-4$ & 2410 & --- & 2559 \\
Ohio Congress & $4-$ & 2 & -- & 2379 & 2443 & 2435 \\
American Open & $5-$ & 3 & -- & 2221 & 2612 & 2446 \\
Cardinal Open & $2.5-$ & 2.5 & -- & 2234 & 2581 & 2392 \\
National Open & $5-$ & 1 & $7-19$ & 2230 & 2640 & 2476 \\
\hline
\end{tabular}

Beside these tournament competitions, Hitech also played, in February, an informal telephone match against Israeli National Master Malchiel Peretz (FIDE 2350) and defeated him 1.5-0.5.

Hitech, performing in tournaments accounted for by FIDE, has shown itself to be fully worthy of a (fairly high) FIDE rating, had it been a human player. However, not being human and in spite of having met every qualification, it was denied such a rating. The absurd result is that, in spite of its fair rating at a potential 2350, Hitech has been excluded from its rightful status of a FIDE master. 